\title{
Fluorescence Properties of Reduced Flavins and Flavoproteins
}

\author{
Antonie J. W. G. VISSER, Sandro GHISLA, Vincent MASSEY, Franz MÜLLER, and Cees VEEGER \\ Department of Biochemistry, Agricultural University, Wageningen
}

\begin{abstract}
Fluorescence lifetimes and polarized emission properties of reduced flavin were measured using several model compounds and flavoproteins. Depending on the conditions of solvent and temperature or reduction method the lifetimes vary between 1 and $15 \mathrm{~ns}$. The longer lifetime values are found in several forms of reduced lactate oxidase, in which a good correlation exists between fluorescence intensity and lifetime. In practically all flavoproteins the fluorescence is heterogeneous. Several mechanisms are proposed to explain the observed heterogeneity in lifetimes. The reduced models in glycerol at subzero temperature exhibit high degrees of polarization of the fluorescence, whereas distinct depolarization is encountered in several reduced flavoproteins suggesting a certain mobility of the flavin chromophor.
\end{abstract}

The flavin molecule is a redox system catalyzing one-electron and two-electron transfer reactions. The catalytic mechanism is still incompletely understood [1]; however, modified forms of the reduced coenzyme are likely to occur as intermediates [2-4]. Thus knowledge of their properties and their characterization may yield valuable information for a better understanding of flavin catalysis.

Reduced flavins and flavoproteins have been shown to exhibit blue to green fluorescence under various conditions [5]. The optical absorption, and especially the emission properties like spectral distribution and quantum yield, are very much dependent on polarity or viscosity of the solvent and $\mathrm{pH}$. Furthermore the nature of the substituent in C-4a and N-5 adducts and the rigidity of the structure of the reduced flavinyl compound seem to be determining factors for the appearance of fluorescence and some absorption features. In order to obtain more detailed information at a molecular level measurements of lifetime and degree of polarization have been performed for a selected number of reduced flavoproteins and flavin models. Experiments of this kind complement the results already obtained with steady-state fluorescence techniques [5] and in addition reveal certain dynamic aspects of the emission of the reduced flavin chromophore.

Enzymes. L-Amino acid oxidase (EC 1.4.3.2); D-amino acid oxidase (EC 1.4.3.3); lactate 2-monooxygenase (EC 1.13.12.4).

\section{MATERIALS AND METHODS}

\section{Enzymes}

Lactate oxidase was prepared from Mycobacterium smegmatis by the method of Lockridge et al. [6]. L-Amino acid oxidase was prepared from Crotalus adamanteus venom by the method of Wellner and Meister [7]. D-Amino acid oxidase was prepared from pig kidneys as described by Curti et al. [8]. Flavodoxin was isolated from Megasphaera elsdenii according to Mayhew et al. [9]. Reduced enzymes were obtained as described by Ghisla et al. [5], essentially by using either substrate, dithionite, or EDTA/light as reducing agents. The reduced lactate oxidase adducts were obtained as already outlined $[2,5,10]$ and as will be detailed elsewhere (S. Ghisla and V. Massey, unpublished results). All reagents used were of analytical grade. Buffer solutions were prepared from doubly distilled water.

\section{Models}

3-Methyl-3,4-dihydrolumiflavin (I) and 1,3,4,5tetrahydrolumiflavin (II) were prepared according to the procedure of Müller et al. [12]. 3-Methyl-4a-isopropyl-4a,5-dihydrolumiflavin (III), was a gift of Professor P. Hemmerich, Konstanz. 3-Methyl-4a,5propano-4a,5-dihydrolumiflavin (IV) was prepared following published procedures [5]. 


\section{Methods}

Absorption spectra were recorded with a Cary model 14 spectrophotometer. Fluorescence spectra were obtained with a Hitachi MPF-2A spectrofluorimeter equipped with a thermostated cell holder.

The degree of polarization of the fluorescence was obtained as described by Visser et al. [13]. The emission was viewed through Schott GG 455 or GG 495 filters. A typical excitation band width was $8 \mathrm{~nm}$.

Fluorescence lifetimes were determined by two methods: phase and modulation fluorometry and single photon decay spectroscopy $[14,15]$. The phase fluorometer has been described by Schürer et al. [16]. Two modulation frequencies $(15$ and $60 \mathrm{MHz})$ were used to check the homogeneity of the lifetimes. The instrument has an accuracy of about $2 \%$ for lifetimes in the range of $0.2-10 \mathrm{~ns}$ for not too weakly emitting species. In most experiments the samples were excited at $360 \mathrm{~nm}$ and the same filters were used as for the polarization measurements. Fluorescence decay curves were obtained with a single photon counting apparatus partly described elsewhere [17]. For excitation the 358-nm line of the air-flash lamp was used, isolated either with a $0.25-\mathrm{m}$ monochromator (Jarrell-Ash 82410 ) or with an interference filter (Balzers $361 \mathrm{~nm}$ ). Depending on the signal intensity the emission was selected either with filters (a combination of Schott KV 418 and GG 455) or with a 0.25 -m monochromator (Jarrell-Ash 82410). Fluorescence decay curves are usually distorted by the finite duration of the exciting pulse and associated detection electronics. The decay curves can be described by the following equation:

$$
\mathrm{F}(t)=\int_{0}^{t} g\left(t-t^{\prime}\right) I\left(t^{\prime}\right) d t^{\prime}
$$

where $F(t)$ is the experimental decay curve, $g(t)$ is the measured instrumental response function and $\mathrm{I}(t)$ the fluorescence decay function following an infinitely short excitation. $I(t)$ is usually of the form

$$
\sum_{j=1}^{n} \alpha_{j} \mathrm{e}^{-1 / \tau_{j}}
$$

with in our case either $n=1$ or $n=2$.

After adjustment of the parameters $\alpha_{j}$ and $\tau_{j}$ the product of $I(t)$ and $g(t)$ is integrated (convolution) and the result, $F_{\mathrm{c}}(t)$, is compared with the experimental curve, $F(t)$. The criterion for 'best fit' was attained after a search for the minimum values of the sum of the weighted squares of the residuals $(\phi)$ and rootmean-squares deviation (RMS).

$$
\phi=-\frac{1}{N_{0}} \sum_{i=1}^{N} W_{i}\left[F(i)-F_{\mathrm{c}}(i)\right]^{2}=\frac{1}{N_{0}} \sum_{i=1}^{N} W_{i} A_{i}^{2},
$$

where the sum is over $N$ channels of the multichannel analyzer, $N_{0}=\frac{1}{N_{0}} \sum_{i=1}^{N} W_{i}$, a normalization factor and
$W_{\mathrm{i}}=1 / F(i)$, the statistical weighting factor in each channel $i$, valid for photon counting data. The rootmean-square deviation is defined by the expression:

$$
\mathrm{RMS}=\left(\frac{1}{N} \sum_{i=1}^{N} A_{i}^{2}\right)^{1 / 2} .
$$

We used the nonlinear least-squares method for deconvolution of the fluorescence decay as outlined by Grinvald and Steinberg [18]. For visual comparison a plot of the residual values of calculated and observed decay curves is generated as well as the autocorrelation function $C(t)$ of the residuals [18]. A good quality of the fits implies that these functions fluctuate around zero.

Because of its wavelength dependence the response function of the apparatus, $g(t)$, was determined with a reference compound by a method described elsewhere [19]. The reference compounds were either a degassed solution of 1,1,4,4-tetraphenyl-1,3-butadiene in cyclohexane or a rigid solution of this compound in polymethyl metacrylate. The lifetime of both samples were measured with the phase fluorometer operating at $60 \mathrm{MHz}$. For the solution in cyclohexane a value of $1.77 \pm 0.05 \mathrm{~ns}$ was obtained in the temperature range of $10-20^{\circ} \mathrm{C}$ and for the plastic solution the lifetime was $2.20 \pm 0.10 \mathrm{~ns}$ between $0^{\circ}$ and $20^{\circ} \mathrm{C}$. The lifetimes were homogeneous with respect to measurements of phase and modulation [14].

The performance of the decay fluorometer was checked by the use of standards having one single fluorescence lifetime [20]. In the blue spectral region $(430-470 \mathrm{~nm})$ anthracene in cyclohexane gave a single lifetime of $4.2 \mathrm{~ns}$ and in the green spectral region $(500-530 \mathrm{~nm})$ measurements of 3-methyllumiflavin in water showed a value of $4.6 \mathrm{~ns}$.

\section{RESULTS}

\section{Degree of Polarization \\ of Reduced Flavins and Flavoproteins}

The degree of polarization $(p)$ of fluorescent compounds can serve as an indicator for intrinsic molecular properties [21]. The presence of submerged electronic transitions in absorption bands can be demonstrated by monitoring the degree of polarization upon variation of excitation wavelength. At a fixed excitation wavelength a value of $p$ lower than the maximum attainable one $\left(p_{0}\right)$ at that wavelength, when the movement of the molecules is frozen during the lifetime of the excited state, suggests a certain degree of mobility of the fluorophor. Both aspects were investigated with model flavins and flavoproteins. As an illustration the dependence of $p$ on the excitation wavelength is given in Fig. 1 for compound III dissolved in glycerol. For comparison the absorption spectrum is also shown. From the polarization excita- 


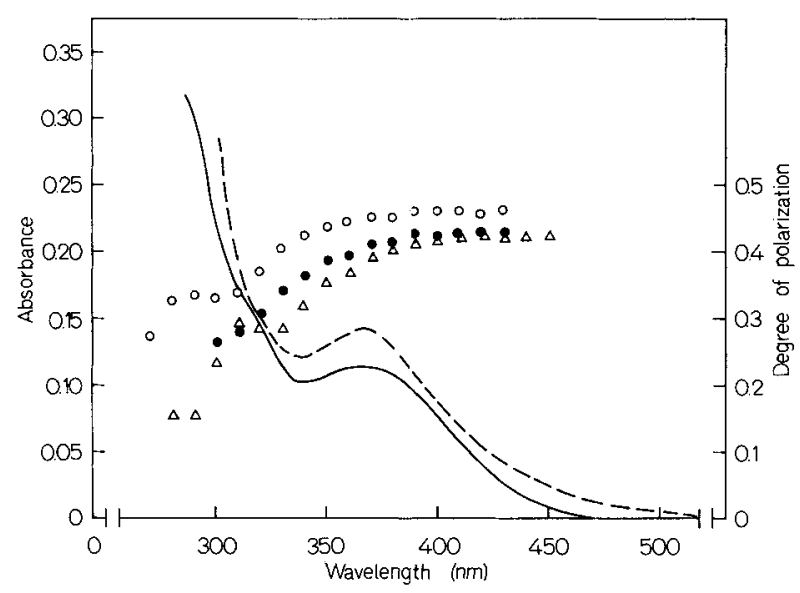

Fig. 1. Polarization excitation spectra and absorption spectra of reduced flavins and flavoproteins. Details as given in text. (-) Absorption spectrum of 3-methyl-4a-isopropyl-4a,5-dihydrolumiflavin dissolved in glycerol, $(\mathrm{O}-\mathrm{O})$ degree of polarization $(p)$ at $-10^{\circ} \mathrm{C}$; -0$) p$ at $22^{\circ} \mathrm{C}$; (---) absorption spectrum of D-amino acid oxidase benzyl adduct; $(\Delta-\Delta) p$ at $22^{\circ} \mathrm{C}$. The absorption spectra were measured at $22^{\circ} \mathrm{C}$

tion spectrum obtained at $-10^{\circ} \mathrm{C}$ a region of constant high values of $p$ between 350 and $430 \mathrm{~nm}$ can be distinguished corresponding to the lowest electronic transition $\left(\mathrm{S}_{0}-\mathrm{S}_{1}\right.$, centered at $\left.365 \mathrm{~nm}\right)$. Between 300 and $350 \mathrm{~nm}$ a gradual decrease in $p$ is observed $\left(\mathrm{S}_{0}-\mathrm{S}_{2}\right.$ around $320 \mathrm{~nm}$ ) reaching again a constant value below $300 \mathrm{~nm}\left(\mathrm{~S}_{0}-\mathrm{S}_{3}\right)$. In the latter'spectral regions one has to deal with polarization directions of higher electronic transitions different from the direction of the first transition moment. Similar overlapping electronic transitions manifested by polarization measurements were observed in the cationic flavins [22]. It is important to note that in the models (I-IV) studied the maximum degree of polarization reaches values up to 0.46 . This is partly due to the short lifetime of the fluorescence (vide infra). It also illustrates that the limiting polarization of reduced flavins can reach high values, which is important for a correct interpretation of the depolarization encountered in flavoproteins. When the temperature is raised from $-10^{\circ} \mathrm{C}$ to $20^{\circ} \mathrm{C}$ a distinct depolarization across the whole excitation region is observed, due to faster Brownian rotations of the reduced flavin chromophore (Fig. 1). The polarization excitation spectrum of the C-4a benzyl adduct of D-amino acid oxidase together with the light absorption spectrum is also shown in Fig. 1. In this sample the degree of polarization is high and constant across the $390-450-\mathrm{nm}$ region $\left(\mathrm{S}_{0}-\mathrm{S}_{1}\right)$. Between 330 and $390 \mathrm{~nm}$ the degree of polarization is decreasing indicating the presence of higher transitions $\left(\mathrm{S}_{0}-\mathrm{S}_{n}, n \geq 2\right)$. Below $330 \mathrm{~nm}$ there is a small constant region followed by a further depolarization. It should be noted that in nearly all weakly emitting reduced flavoproteins prepared by reduction by substrates, the degree of polarization is highest when a substoichiometric amount of sodium dithionite is added to the anaerobic solution. This observation is probably related to the fact that reduction by substrate leaves a small amount of enzyme unaffected. This enzyme is catalytically inactive but contains oxidized flavin causing the depolarization. In Table 1 the maximum observed degree of polarization with the inherent excitation wavelength for a number of flavoproteins has been collected. The data were obtained similarly as illustrated in Fig. 1 for the benzyl adduct. The maximum value is usually measured at the red edge of the absorption spectrum where the overlap with the second electronic transition is minimum. The reduced lactate oxidase can be considered as an example of a 1,5-dihydroflavin. In the enzyme the degree of polarization is almost continuously decreasing from $0.42 \mathrm{~nm}$ at $440 \mathrm{~nm}$ to a value of $0.32 \mathrm{~nm}$ at $350 \mathrm{~nm}$. This indicates a mixed polarization at wavelengths below $420 \mathrm{~nm}\left(\mathrm{~S}_{0}-\mathrm{S}_{n}, n>1\right)$ and a rather small angle between the transition moments. Between $320 \mathrm{~nm}$ and $350 \mathrm{~nm}$ there is even a small increase in $p(0.33)$ followed by a distinct depolarization when the excitation is in the light-absorbing region of the protein $(<320 \mathrm{~nm})$. Noteworthy is the expected depolarization observed in the reduced flavodoxin (Table 1) as a result of the small molecular weight of this protein (15000). The acyl adducts from both D-amino acid oxidase and L-amino acid oxidase show a larger depolarization than observed when these enzymes are reduced with $\mathrm{NaBH}_{4}$ or with phenylacetic acid in the presence of light. This suggests a higher flexibility of the acyl derivative in these proteins. Generally, the polarization values obtained in model flavin compounds dissolved in glycerol are much higher than the ones observed in flavoproteins. Even the reduced forms of lactate oxidase with its high molecular weight of 330000 never showed $p$ values higher than 0.42 . In view of the high $p_{0}$ values that can be attained in model flavins this might indicate a certain segmental mobility of the flavin in this flavoprotein. On the other hand, the enzyme appears as an octamer in the oxidized state but might have different degrees of association upon reduction.

By comparing the spectra of $4 \mathrm{a}, 5$-dihydroflavin and 1,5-dihydroflavin (see [5]) it is noteworthy that the bands show poor vibrational fine structure. Furthermore the poor overlap between absorption and emission spectra even at low temperature indicates a large Stokes' loss. This might reflect a change in geometry in the excited state. As pointed out by Steinberg, the vibrational transitions within a certain electronic band can be polarized differently [23]. Vibrational depolarization within the lowest electronic absorption band is not directly apparent in the model compounds studied. Vibronic transitions within a single electronic band are sensitive to vibrational 


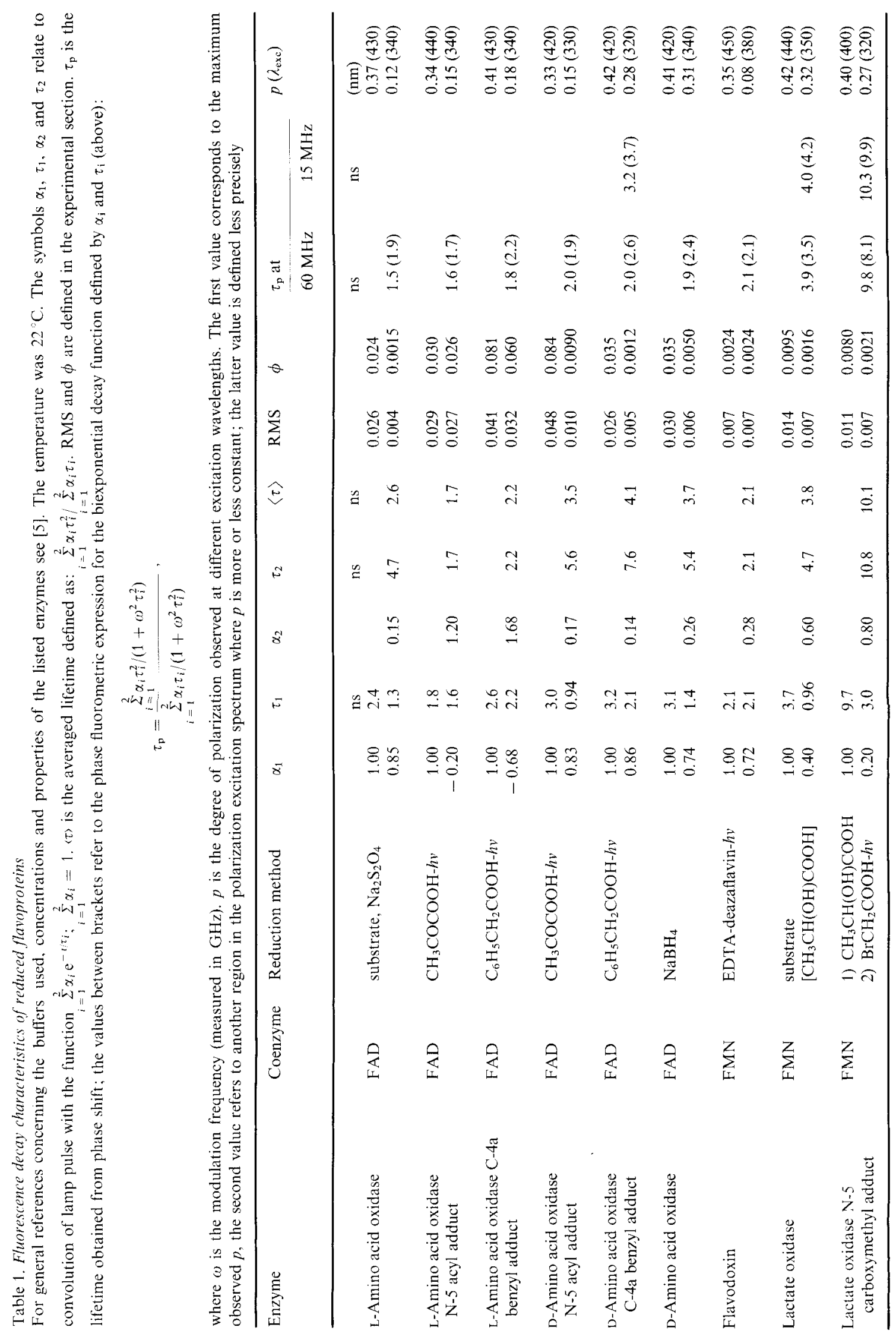


perturbations, e.g. induced by the protein in the bound chromophore [23]. The polarization spectrum of the emission band may give valuable information concerning structural changes in the excited state. However, because of problems with sensitivity the experiments were limited to selective excitation using all of the fluorescence light. Careful selection of both excitation and emission wavelengths awaits further improvement of instrumentation.

\section{Fluorescence Decay Characteristics of Reduced Flavins and Flavoproteins}

As with the polarization experiments, in order to remove parasitic fluorescence a substoichiometric amount of dithionite was added to the solutions studied. Generally, the fluorescence decay of most reduced forms cannot be considered as a single exponential, but in many cases reasonable fits were obtained by assuming a decay function consisting of a sum of two exponential terms. Without detailed knowledge of the mechanism giving rise to deviation from monoexponentiality, it is at this stage not meaningful to analyze the data with decay functions different from single and double exponentials. In Fig. 2 several samples are shown: photoalkylated D-amino acid oxidase and lactate oxidase. In these two proteins the assumption of two lifetimes leads to improvement of the fit between calculated and experimental curves as judged from lower $\phi$ and RMS values and from the shapes of the weighted residual and autocorrelation functions. However, in cases where the lamp pulse width is equal or longer than both lifetimes, complications arise with fitting procedures sometimes not leading to unequivocal data (Table 1). For example, the quality of fits with adducts of $\mathrm{L}$-amino acid oxidase hardly improves assuming a doubleexponential decay. The negative pre-exponential factors probably have no physical meaning in this case. Except for reduced flavodoxin the decay of all flavoproteins consists of a short and a long lifetime component with unequal amplitudes. The second-order averaged lifetime $(\langle\tau\rangle)$ and the lifetimes obtained with phase fluorometry are collected in Table 1 . We also included in Table 1 the phase lifetimes (values between brackets) that can be expected when the two lifetimes and amplitudes obtained from fluorescence decay are substituted in the phase-fluorometric expression for a biexponential decay function. In the latter technique using $60 \mathrm{MHz}$ it is clear that more weight is given to the component with the shortest lifetime. Bearing this in mind the agreement between the results obtained with two entirely different methods is satisfactory. Some results obtained with phase fluorometry at $15 \mathrm{MHz}$ also points to heterogeneity of lifetimes, e.g. the C-4a benzyl adduct of D-amino acid oxidase and the $\mathrm{N}-5$ carboxymethyl photoadduct of lactate oxidase.
With regard to the latter the averaged lifetime as calculated from decay profiles is very close to the one measured with phase fluorometry at $15 \mathrm{MHz}$. This result can be expected since in a complex decay the averaged lifetime is better represented by the value obtained at lower modulation frequencies. The lifetimes as measured at two different modulation frequencies of the substrate-reduced lactate oxidase are very close and in good agreement with the averaged lifetime obtained from fluorescence decay. It is definitely an advantage to compare both methods for obtaining fluorescence lifetimes. The advantages and disadvantages of phase and pulse fluorometry have been summarized elsewhere [24]. The fact that both techniques applied to single exponentially decaying flavin models gave rise to similar lifetimes strenghtens the reliability of the results [24]. A critical evaluation of the merits of the two different techniques in heterogeneous decay is preserved for a separate publication (A. J.W. G. Visser, unpublished).

In Table 2 phase fluorometric data of four model compounds are collected. A significant difference between the lifetimes of 3,4-dihydrolumiflavin (compound I) in buffer solution at $\mathrm{pH} 7.0$ and in glycerol is observed. Addition of two further electrons (compound II) leads to shortening of lifetimes. The data obtained with the other two model compounds III and IV illustrate the large sensitivity of the lifetimes on temperature and viscosity of the solvent.

\section{Decay Experiments Conducted with Different Covalent Adducts of Reduced Lactate Oxidase}

Lactate oxidase has been found to react with the prochiral substrate glycollate and to form two different covalent adducts of the reduced coenzyme, which are markedly different in their chemical properties, but have similar static fluorescence and absorption characteristics [2]. These two different species were found to be the enantiomeric ( $\mathrm{re}$ )-glycollyl and (si)-glycollyl adducts to the reduced enzyme [2]. In view of the importance of such intermediates for the investigation of the enzymatic reaction mechanisms, their dynamic fluorescence properties were investigated providing a simple means for their characterization and differentiation.

A typical example is shown in Fig. 3. All results obtained with the different adducts are summarized in Table 3. The first striking point is the observation of two different lifetimes with each adduct, independently of the mode preparation (cf. Table 3 ). The enzyme does not undergo irreversible inactivation during turnover with glycollate apart from the accumulation of the si adduct, and formation of the inhibitor oxalate [10]; thus this seems to preclude the 


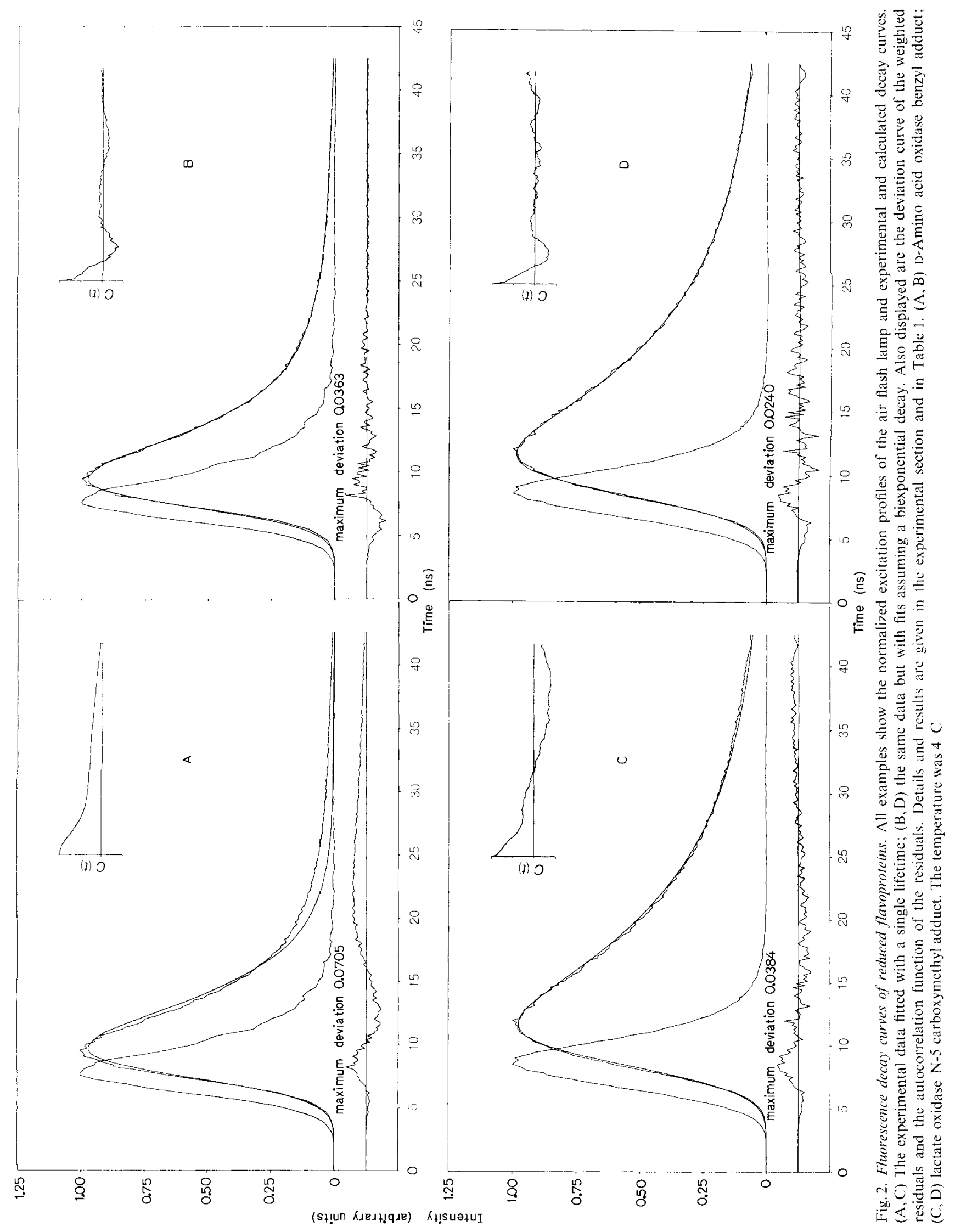


Table 2. Fluorescence lifetimes of some reduced model flavins The values were obtained from phase fluorometry at $60 \mathrm{MHz}$. The names of the compounds are given in the experimental section. When the solvent was water, it contained $0.1 \mathrm{M}$ sodium phosphate $\mathrm{pH} 7.0$

\begin{tabular}{lll}
\hline Compound & No. Solvent $\begin{array}{l}\text { Temper- } \tau \\
\text { ature }\end{array}$ \\
\hline
\end{tabular}<smiles>Cc1cc2c(cc1C)N(C)C1=NC(=O)N(C)C(O)C1=N2</smiles><smiles>Cc1cc2c(cc1C)n(C)c(=O)[nH]c1c(n2C)NC1O</smiles>

II glycerol $22 \quad 1.3$<smiles>Cc1cc2c(cc1C)N(C)C1(C(C)C)C(=O)N(C)C(=O)N=C2N1C</smiles>

III glycerol $-10 \quad 2.6$

$\begin{array}{rr}0 & 1.5 \\ 22 & 1.1\end{array}$<smiles>CCN1c2cc(C)c(C)cc2N(C)C2=NC(=O)N(C)C(=O)C21CC</smiles>

IV glycerol $-10 \quad 0.98$

0.67

0.36 presence of enzyme populations of different activity. In general, the introduction of a substituent into the $\mathrm{N}-5$ position appears to increase the (average) lifetime of the fluorescent chromophore. This is particularly evident in the case of the N-5 carbonate adduct, in which the N-5 nitrogen is part of an amide linkage. The covalent N-5 adducts of different chirality appear in fact to possess different dynamic fluorescence prop-

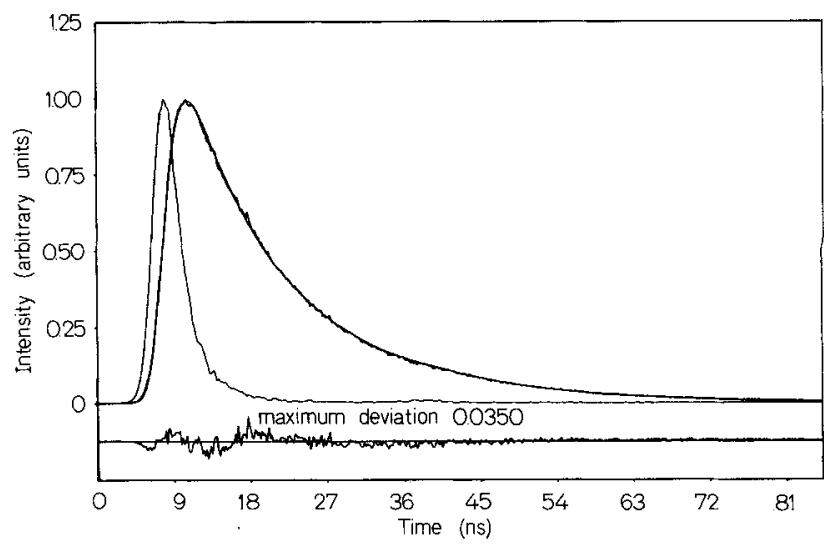

Fig. 3. Fluorescence decay profile during a particular stage of adduct formation of lactate oxidase: addition product of glycollate, after anaerobic mixing $\left(4^{\circ} \mathrm{C}\right)$, warming up at $30^{\circ} \mathrm{C}$ during 5 min and equilibration with air. Only a biexponential fit is shown superimposed on the experimental curve. For further details see the legend of Fig. 2. Results are given in Table 3. The peak maximum contains 12774 counts, the measuring time was $22 \mathrm{~min}$, the temperature was $22^{\circ} \mathrm{C}$

Table 3. Fluorescence lifetimes of covalent derivatives of reduced lactate oxidase

For the procedures of preparation and general characteristics of these adducts see $[2,5,10]$. Enzyme concentrations: $30 \mu \mathrm{M} ; \lambda_{\mathrm{exc}}=358 \mathrm{~nm}$. $\lambda_{\mathrm{em}}=475$ or $460 \mathrm{~nm}$, ef. also Fig. 3 and 4 . The symbols are defined in Table 1 . The temperature given is that of the decay experiment

\begin{tabular}{|c|c|c|c|c|c|c|c|c|c|}
\hline Structure of adduct & $\begin{array}{l}\text { Mode of adduct formation and } \\
\text { composition of adduct }\end{array}$ & $\alpha_{1}$ & $\tau_{1}$ & $\alpha_{2}$ & $\tau_{2}$ & $\langle\tau\rangle$ & RMS & $\phi$ & $\begin{array}{l}\text { Temper- } \\
\text { ature }\end{array}$ \\
\hline & & & ns & & ns & ns & & & ${ }^{\circ} \mathrm{C}$ \\
\hline $\mathrm{N}-5 \mathrm{COO}^{-}$ & $\begin{array}{l}\text { oxidized enzyme }+\left(\mathrm{COO}^{-}\right)_{2} \\
\quad+h v\left(4^{\circ} \mathrm{C}\right)\end{array}$ & 0.56 & 2.4 & 0.44 & 17.3 & 15.1 & 0.007 & 0.0033 & 4 \\
\hline $\mathrm{N}-5 \mathrm{CH}_{2} \mathrm{COO}^{-}$ & $\begin{array}{l}\text { substrate-reduced enzyme } \\
\quad+\mathrm{BrCH}_{2}-\mathrm{COO}^{-}, h v \text { then } \\
\text { air equilibrated }\end{array}$ & 0.69 & 1.4 & 0.31 & 15.2 & 12.8 & 0.010 & 0.0082 & 4 \\
\hline $\begin{array}{l}\mathrm{N}-5 \mathrm{CH}-\mathrm{COO}^{-} \\
\quad \mathrm{OH} \\
\text { "si adduct' } 2\end{array}$ & $\begin{array}{l}\text { oxidized enzyme } \\
\quad+\mathrm{CH}(\mathrm{OH})\left(\mathrm{COO}^{-}\right)_{2}, h v\left(4^{\circ} \mathrm{C}\right)\end{array}$ & 0.46 & 2.5 & 0.54 & 9.5 & 8.2 & 0.006 & 0.0021 & 4 \\
\hline \multirow[t]{3}{*}{$\begin{array}{l}\mathrm{N}-5 \mathrm{CH}-\mathrm{COO} \\
\quad \mathrm{OH} \\
\text { (mixture of adducts } \\
\text { and of free reduced } \\
\text { enzyme) }\end{array}$} & $\begin{array}{l}\text { oxidized enzyme }+ \text { glycollate: } \\
\text { (a) } 15 \text { min after mixing }(4 \mathrm{C}) \\
\text { (mainly re adduct }+ \text { some } \\
\text { si adduct and some reduced } \\
\text { enzyme) }\end{array}$ & 0.68 & 1.7 & 0.32 & 16.0 & 13.4 & 0.008 & 0.0037 & 4 \\
\hline & $\begin{array}{l}\text { (b) heated at } 30^{\circ} \mathrm{C} \text { for } 5 \mathrm{~min} \\
\text { (mainly si adduct }+ \text { some re } \\
\text { adduct and reduced enzyme) }\end{array}$ & 0.66 & 2.1 & 0.34 & 12.3 & 9.7 & 0.007 & 0.0027 & 22 \\
\hline & $\begin{array}{l}\text { (c) equilibrated with air (mainly } \\
\text { si adduct }+ \text { some re adduct) }\end{array}$ & 0.47 & 3.1 & 0.53 & 13.5 & 11.7 & 0.007 & 0.0025 & 22 \\
\hline
\end{tabular}




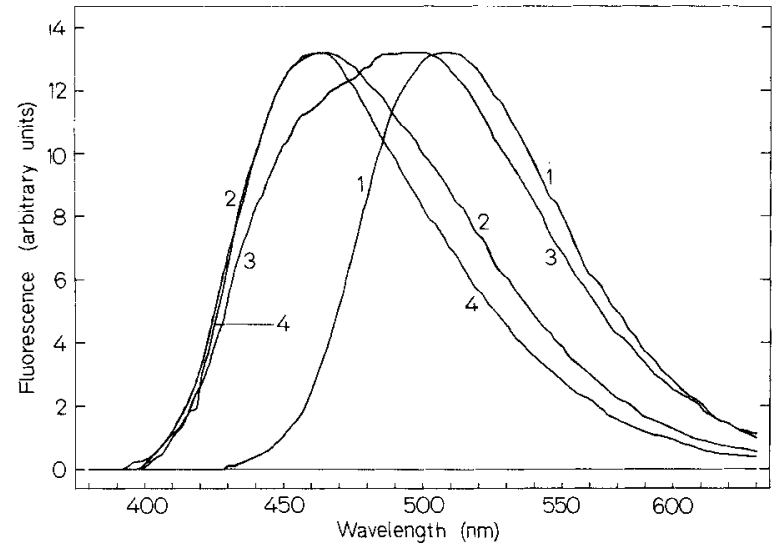

Fig. 4. Spectral changes upon anaerobic addition of glycollate to lactate oxidase. The emission spectra are normalized. Curve 1: flavin reduced with excess DL-lactate; curve 2: addition product measured at $15 \mathrm{~min}$ after anaerobic mixing; curve 3 : heated at $30^{\circ} \mathrm{C}$ for $5 \mathrm{~min}$; curve 4: after admission of air. Conditions as mentioned in Table 3

erties. The 'clean' si adduct (cf. Table 3 ) has a much shorter lifetime than the mixture in which the re species represents the main component [2]. Unfortunately, a quantitative evaluation of the components of an adduct mixture is not readily feasible considering the presence of two decay modes for each single adduct. However, a qualitative estimation is possible when the lifetimes are correlated with the emission spectra (Fig.4), which were recorded at the same intervals as employed for registration of the decay curves. From the curves of Fig. 4, in which the emission spectrum of substrate-reduced lactate oxidase (curve 1) is included for comparison, it follows that different emitting species are present at the three stages of the experiment outlined in Table 3. In particular the very broad spectrum of curve 3 (Fig. 4 ) is characteristic for a mixture also containing normally reduced enzyme.

\section{DISCUSSION}

The results presented here support the previous conclusions [5] that at least two electronic transitions are undoubtedly present in the absorption spectra of reduced flavins and flavoproteins in the region $>300 \mathrm{~nm}$ as judged from different polarization directions. There is not much difference in the polarization results with respect to free and variously substituted reduced flavins. In the present case the absolute direction of the transition moment in the molecular framework corresponding to the lowest electronic transition cannot be determined using rigid solutions of randomly oriented molecules. However, because of the high degree of polarization encountered in some model flavins the transition moment should be more or less located in the plane of the reduced chromophore. The significant depolarization of the fluorescence observed in many flavoproteins suggests a not yet defined type of motion that the reduced flavin undergoes during the time scale of the fluorescence experiment. Probably this mobility is different from the well-known bufferfly or inversion type movements [25].

The observation that the fluorescence is enhanced in a more rigid structure can also be extrapolated to the lifetimes. The more fluorescence, the longer the lifetimes as it should be according to the fundamental relationship between fluorescence lifetime $(\tau)$ and quantum yield $(Q): \tau / \tau_{0}=Q\left(\tau_{0}=\right.$ radiative lifetime $)$. This is nicely illustrated by comparing the averaged lifetimes of lactate oxidase, in which the adduct exhibits a $2-3$ times longer lifetime than the flavin hydroquinone bound to the enzyme. The temperature dependence of the lifetimes is demonstrated in the experiment where the model compounds III and IV exhibit a more than $100 \%$ change in lifetime upon variation of temperature over $30^{\circ} \mathrm{C}$. The extreme sensitivity of the fluorescence yields and lifetimes with the temperature and viscosity of the solvent might be the reason that the emission parameters of the reduced flavoproteins studied can adopt such divergent values. Environmental factors and the amount of constraint imposed by the protein can be determining for the appearance of fluorescence. On the other hand, enhanced vibrational freedom or mobility can provide additional channels for radiationless decay to the ground state leading to drastic quenching of the fluorescence.

The heterogeneity of the fluorescence lifetimes may be interpreted in two general ways. Firstly, the heterogeneity originates from the presence of different emitting species. A clear example is the benzyl adduct of D-amino acid oxidase where, depending on the conditions of preparation, the addition takes place either predominantly at N-5 or at C-4a [26]. Since both forms are chemically distinguishable the emission spectra as well as the lifetimes of the species involved should be different. Another example is given by the covalent N-5 adducts of different chirality as found in lactate oxidase. The microenvironments of the stereoisomers in the protein are different. Consequently, the adducts are characterized by different lifetimes. They possess, however, similar static fluorescence spectra [2]. A final possibility is the presence of a mixture of reduced enzyme and adduct as is evident in some preparations of lactate oxidase. The second explanation takes into account dynamic processes, which influence the decay mechanism of the 'unperturbed' chromophore. Protonation in the excited state is one of these phenomena, that can affect the kinetics of the fluorescence substantially [27]. For reduced flavin in solution the proton at $\mathrm{N}-1$ is the most acid one (ground state $\mathrm{p} K \approx 6.5$ [28]. The $\mathrm{p} K$ in the excited state $\left(\mathrm{p} K^{*}\right)$ is generally quite different from that in the ground state [27]. From the ab- 
sorption spectra of anionic and neutral reduced flavins as obtained previously [5] an estimate of the $\mathrm{p} K^{*}$ value can be made by application of the so-called Förster cycle [29]:

$$
\mathrm{p} K^{*}=\mathrm{p} K-\frac{0.625}{T} \Delta \bar{v}
$$

with $\Delta \bar{v}$ the frequency difference between the longwavelength absorption bands of neutral and anionic forms of flavin hydroquinone. If $T$ is taken as $295 \mathrm{~K}$ the difference, $\Delta \mathrm{p} K=\mathrm{p} K^{*}-\mathrm{p} K$, amounts to only -1.4 . However one should bear in mind that $\Delta \mathrm{p} K$ might change drastically upon interactions with charged groups near the reduced flavin in the different flavoenzymes. The anionic species might fluorescence in time with a sum of two exponentials, whereas the fluorescence of the neutral reduced flavin (formed in the excited state) can be characterized with a double exponential decay law consisting of equal preexponential factors opposite in sign $[27,30]$. An important consequence of the small $\Delta \mathrm{p} K$ is that the emission spectra of both species overlap considerably. The neutral reduced flavin cannot be distinguished from the anionic form so that the observed decay pattern becomes very intricate. In reduced lactate oxidase the emitting population might consist of neutral and anionic flavin hydroquinone. Of course, other dynamic processes, like rapid quenching by amino acid residues in the protein [31] or the flexing inversion along N-1 $\mathrm{N}-5$ [25], cannot be ruled out.

In order to corroborate the mechanism that is in operation each individual reduced flavin system as surveyed in this report should be studied in more detail using different experimental approaches.

We are indebted to Professor P. Hemmerich for a gift of one of the reduced flavin models. We wish to thank Mr B. J. Sachteleben for drafting and Mrs J.C. Toppenberg-Fang for typing the manuscript. This work was supported in part by the Netherlands Foundation for Chemical Research (S.O.N.) with financial aid from the Netherlands Organization for the Advancement of Pure Research (Z.W.O.) and by N.A.T.O. grant 912 (D1935).

\section{REFERENCES}

1. Singer, T. P. (ed.) (1976) Flavins and Flavoproteins, Proceedings of the fifth International Symposium, Elsevier Publishing Company, Amsterdam.

2. Ghisla, S. \& Massey, V. (1978) in Mechanisms of Oxidizing Enzymes (Singer, T. P. \& Ondarza, R., eds) pp. 55-68, Elsevier Publishing Company, Amsterdam.
3. Hastings, J. W., Balny, C., Le Peuch, C. \& Douzou, P. (1973) Proc. Natl Acad. Sci. U.S.A. 70, 3468-3472.

4. Entsch, B., Ballou, D. P. \& Massey, V. (1976) J. Biol. Chem. $251,2550-2563$.

5. Ghisla, S., Massey, V., Lhoste, J. M. \& Mayhew, S. G. (1974) Biochemistry, 13, 589-597.

6. Lockridge, O., Massey, V. \& Sullivan, P. A. (1972) J. Biol. Chem. 247, 8097-8106.

7. Wellner, O. \& Meister, A. (1960) J. Biol. Chem. 235, 20132018.

8. Curti, B., Ronchi, S., Branzoli, U., Ferri, G. \& Williams, C. H. (1973) Biochim. Biophys. Acta, 327, 266-273.

9. Mayhew, S. G., Foust, G. P. \& Massey, V. (1969) J. Biol. Chem. 244, 803-810.

10. Ghisla, S. \& Massey, V. (1975) J. Biol. Chem. 250, 577-584.

11. Reference deleted.

12. Müller, F., Massey, V., Heizmann, C., Hemmerich, P., Lhoste, J. M. \& Gould, D. C. (1969) Eur. J. Biochem. 9, 392-401.

13. Visser, A. J. W. G., Grande, H. J., Müller, F. \& Veeger, C. (1974) Eur. J. Biochem. 45, 99-107.

14. Spencer, R. D. \& Weber, G. (1969) Ann. N.Y. Acad. Sci. 158, $361-376$.

15. Ware, W. R. (1971) in Creation and Detection of the Excited State (Lamola, A. A., ed.) vol. 1A, chapter 5, Marcel Dekker, New York.

16. Schürer, K., Ploegaert, P. G. F. \& Wennekens, P. G. M. (1976) J. Sci. Instrum. 9, $821-824$.

17. Scouten, W. M., De Graaf-Hess, A. C., De Kok, A., Grande, H. J., Visser, A. J. W. G. \& Veeger, C. (1978) Eur. J. Biochem. 84, 17-25.

18. Grinvald, A. \& Steinberg, I. Z. (1974) Anal. Biochem. 59, 583-598.

19. Wahl, Ph., Auchet, J. C. \& Donzel, B. (1974) Rev. Sci. Instrum. $45,28-32$.

20. Grinvald, A. (1976) Anal. Biochem. 75, 260-280.

21. Weber, G. (1969) in Fluorescence and Phosphorescence Analysis (Hercules, D. M., ed.) pp. 217-240, Interscience, New York.

22. Visser, A. J. W. G. \& Müller, F. (1979) Helv. Chim. Acta, 62 , $593-608$.

23. Steinberg, I. Z. (1975) in Concepts in Biochemical Fluorescence (Chen, R. F. \& Edelhoch, H., eds) vol. 1, pp. 70-113. Marcel Dekker, New York.

24. Visser, A. J. W. G. \& Müller, F. (1980) Methods Enzymol. 66E, in the press.

25. Tauscher, L., Ghisla, S. \& Hemmerich, P. (1973) Helv. Chim. Acta, 56, 630-644.

26. Walker, W. H., Hemmerich, P. \& Massey, V. (1970) Eur. J. Biochem. 13, 258-266.

27. Loken, M. R., Hayes, J. W., Gohlke, J. R. \& Brand, L. (1972) Biochemistry, 11, 4779-4786.

28. Michaelis, L. \& Schwarzenbach, G. (1938) J. Biol. Chem. 123, $527-542$.

29. Weller, A. (1961) Progress in Reaction Kinetics, vol. 1, pp. 187 214, Pergamon Press, London.

30. Gafni, A., Modlin, R. L. \& Brand, L. (1976) J. Phys. Chem. 80, 898-904.

31. Grinvald, A.\& Steinberg, I. Z. (1974) Biochemistry, 13, $5170-$ 5178.

A. J. W. G. Visser, F. Müller, and C. Veeger*, Laboratorium voor Biochemie, Landbouwhogeschool,

De Dreijen 11, NL-6703 BC Wageningen, The Netherlands

S. Ghisla, Fachbereich Biologie, Universität Konstanz,

Universitätstraße 10, D-7750 Konstanz, Federal Republic of Germany

V. Massey, Department of Biological Chemistry, University of Michigan Medical School,

Ann Arbor, Michigan, U.S.A. 48109

* To whom correspondence should be addressed. 